\title{
A Computer Oriented Single-Fingerprint Identification System
}

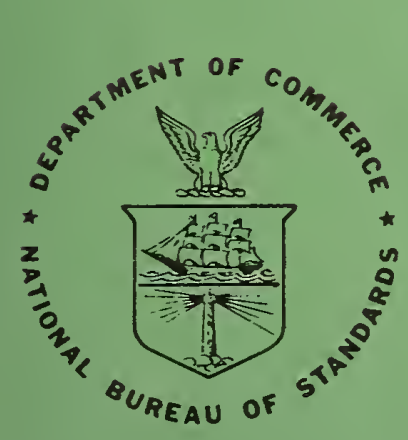

U.S. DEPARTMENT OF COMMERCE National Bureau of Standards 


\section{THE NATIONAL BUREAU OF STANDARDS}

The National Bureau of Standards ${ }^{1}$ provides measurement and technical information services essential to the efficiency and effectiveness of the work of the Nation's scientists and engineers. The Bureau serves also as a focal point in the Federal Government for assuring maximum application of the physical and engineering sciences to the advancement of technology in industry and commerce. To accomplish this mission, the Bureau is organized into three institutes covering broad program areas of research and services:

THE INSTITUTE FOR BASIC STANDARDS . . . provides the central basis within the United States for a complete and consistent system of physical measurements, coordinates that system with the measurement systems of other nations, and furnishes essential services leading to accurate and uniform physical measurements throughout the Nation's scientific community, industry, and commerce: This Institute comprises a series of divisions, each serving a classical subject matter area:

-Applied Mathematics-Electricity-Metrology-Mechanics-Heat-Atomic Physics-Physical Chemistry-Radiation Physics-Laboratory Astrophysics ${ }^{2}$-Radio Standards Laboratory, ${ }^{2}$ which includes Radio Standards Physics and Radio Standards Engineering-Office of Standard Reference Data.

THE INSTITUTE FOR MATERIALS RESEARCH ... conducts materials research and provides associated materials services including mainly reference materials and data on the properties of materials. Beyond its direct interest to the Nation's scientists and engineers, this Institute yields services which are essential to the advancement of technology in industry and commerce. This Institute is organized primarily by technical fields:

-Analytical Chemistry-Metallurgy-Reactor Radiations-Polymers-Inorganic Materials-Cryogenics ${ }^{2}$-Office of Standard Reference Materials.

THE INSTITUTE FOR APPLIED TECHNOLOGY ... provides technical services to promote the use of available technology and to facilitate technological innovation in industry and government. The principal elements of this Institute are:

-Building Research-Electronic Instrumentation-Technical Analysis-Center for Computer Sciences and Technology-Textile and Apparel Technology Center-Office of Weights and Measures -Office of Engineering Standards Services-Office of Invention and Innovation-Office of Vehicle Systems Research-Clearinghouse for Federal Scientific and Technical Information ${ }^{3}$-Materials Evaluation Laboratory-NBS/GSA Testing Laboratory.

${ }^{1}$ Headquarters and Laboratories at Gaithersburg, Maryland, unless otherwise noted; mailing address Washington, D. C., 20234.

${ }^{2}$ Located at Boulder, Colorado, 80302.

${ }^{3}$ Located at 5285 Port Royal Road, Springfield, Virginia 22151. 


\title{
UNITED STATES DEPARTMENT OF COMMERCE
}

Alexander B. Trowbridge, Secretary

NATIONAL BUREAU OF STANDARDS - A. V. Astin, Director

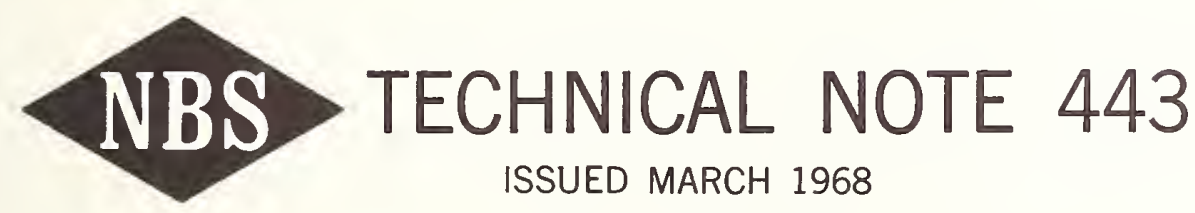

\section{A Computer Oriented Single-Fingerprint Identification System}

\author{
J. H. Wegstein \\ Center for Computer Sciences and Technology \\ Institute for Applied Technolgy \\ National Bureau of Standards \\ Washington, D.C. 20234
}

NBS Technical Notes are designed to supplement the Bureau's regular publications program. They provide a means for making available scientific data that are of transient or limited interest. Technical Notes may be listed or referred to in the open literature. 

A Computer Oriented Single-Fingerprint Identification System

by J.H. Wegstein

A procedure is described for computing a set of numerical descriptors that identify a single fingerprint. The procedure starts with the $\mathrm{X}$ and $Y$ coordinates and the individual directions of the minutiae (ridge endings and bifurcations) of a fingerprint impression. Sets of descriptors are computed corresponding to groups or constellations of these minutiae. Descriptors corresponding to various fingerprint impressions are stored on magnetic tape. A fragment of a fingerprint impression such as occurs in a latent fingerprint may also be used.

A second computer program reads the descriptors corresponding to two different fingerprint impressions from magnetic tape. A score is computed that indicates how well the two impressions match. Preliminary experimental results suggest that this procedure might be suitable as a basis for a singlefingerprint classification system.

Key words: Classification, computer, descriptor, file, fingerprint, identification, pattern-recognition.

\section{Introduction}

In all of the fingerprints ever studied, no two impressions from different fingers have ever been found to be identical in minute detail. Furthermore, the minute details or minutiae of a fingerprint never change throughout the normal life of a finger. Accordingly, the single fingerprint invites increased attention as a means for human identification where tools such as the electronic digital computer are available to handle the information that can be related to the fingerprint impression.

Numerous schemes exist whereby a classification or set of descriptive symbols is developed which describe the fingerprints of a particular individua1. The classification is usually kept on the same standard eight inch square card with the ten fingerprints of an individual, and a collection of these cards can be ordered and filed according to the classification. Then, starting with the fingerprints of an unknown person, a classification can be made and the file can be searched for a matching classification. Several identical classifications may be found in the file and a comparison of the fingerprints is then required to uniquely identify the individual. 
The Henry Classification System ${ }^{1}{ }^{\circ}$ with modern extensions is widely used for large fingerprint collections. It takes account of the different patterns (arch, loop, whorl) and also depends on ridge counts between the core and delta of loops and whorls. The Henry system utilizes information from all ten fingers and consequently, a file cannot be searched for a single fingerprint. The Henry system also requires the classifier to recognize readily the basic patterns as well as cores and deltas. These recognition problems are serious obstacles in any effort to automate the Henry system.

The search for a suitable method for automatically scanning and classifying fingerprints has led to another aspect of fingerprint work: identification. Two fingerprints can be shown to belong to the same finger by comparing a few minutiae such as ridge endings, bifurcations or forks in ridges, incipient ridges, islands, and enclosures. Authorities generally regard the demonstration of 12 correspondences of minutiae (and of course no discordances) as proof that two prints originate from the same finger. 2. While the minutiae are distributed throughout the fingerprint, an identification can be made using the minutiae from any portion of the print. Thus a classification system using minutiae might even be used in searching for fingerprints corresponding to chance prints or latent prints where only a portion of the fingerprint is available. This paper describes a fingerprint identification system based on only two types of minutiae: ridge endings and bifurcations. There are about 93 such minutiae in the fingerprint shown in Figure 1. Four of these are labeled.

In the work reported in this paper the minutiae data are read manually. A set of descriptors is then computed and stored along with a label identifying the fingerprint on magnetic tape as shown in Figure 2. (A magnetic disc, drum, or other mass storage device could of course be substituted for the magnetic tape.)

After several sets of descriptors have been stored in the file, the file may be searched for a particular set of descriptors. The crux of the searching procedure is a matching program and Figure 2 illustrates the set-up used for experimenting with the matching program which is also described in this paper. An operator types in the identifying labels of two fingerprints that are known to be in the file. The matcher then reads the corresponding sets of descriptors from the file and computes a score, ST, which indicates how well the two sets match. The descriptors of a fingerprint can thus be compared with the descriptors of another fingerprint from the same or from a different finger. This paper does not deal with the problem of classifying and ordering the descriptors in the file for the purpose of minimizing search time. 


\section{Taking Minutia Data}

Since a ridge ending in one fingerprint may appear as a bifurcation in another fingerprint from the same finger, no distinction is made between ridge endings and bifurcations in recording data. For each of these minutiae both a location and direction are defined as shown in Figure 3. If the areas marked $B$ are considered as ridges, then point $P$ is the location of a ridge ending and the line GP defines the direction of this minutia. If the areas marked $A$ are considered as ridges, then point $P$ is the location of a bifurcation, and the line GP defines the direction associated with this minutia. Hopefully, an automatic scanning device will soon be available which can scan a fingerprint and record the coordinates and directions of all of its minutiae.

In the work reported here, each fingerprint impression is photographed and enlarged by a factor of 10 . The minutiae on each of these enlargements are then marked with a pencil on a piece of transparent plastic laid over the enlargement. Figure 4 shows the minutiae from an impression hereafter identified as II-W-1. Figure 5 shows minutiae from impression II-W-2 shown in Figure 1. Both impressions are from the same finger but were taken about two months apart. Each minutia is numbered for convenience in studying the identification system, but in an operating system the numbering is unnecessary.

Each transparency is next taped to a drawing board so that all minutiae markings fall in the first quadrant of an X-Y coordinate system as shown in Figure 6. The exact position is not critical. The X and $Y$ coordinates of each minutia are then read in millimeters and recorded. The angle $\theta$ which the minutia direction makes with the $X$ axis is recorded in degrees. Figure 7 shows a portion of this minutia data which is used for demonstrating this identification system. This is similar to the situation that would exist if only a part of the pattern were available in a latent fingerprint for searching against a fingerprint file. Note that the core and delta data are not needed in this system.

\section{Computation of Descriptors}

The complete logical details of the computer program for computing the descriptors that describe the impression are given in Flow Charts 1 through 5. A block diagram of the various steps is given in Figure 8.

The computer first reads in the identification and minutiae data for an impression such as that for impression II-W-1 shown in the left half of Figure 7 . 


\subsection{Constellation Generator}

As detailed in Flow Chart 1, each minutia point is taken as a focal point for a constellation of neighboring points. All points which are within a distance $d$ of the focal point are considered for inclusion in the constellation. Each of those points is actually included in the constellation provided that its non-directed minutia angle ( $\theta$ or $\theta-180$ ) differs by less than $\alpha$ degrees from the non-directed minutia angle ( $\theta$ or $\theta-180$ ) of the focal point. Next, each point that is now in the constellation is in turn considered as a focal point and all data points are examined according to the above criteria to see if they too should be added to the constellation. However, all angles are compared to the minutia angle of the original focal point. As a result of the above procedure, minutia point 2 serves as a focal point for a constellation that includes points $2,4,5$, and 8 as shown in Column $E_{1}$ in the left half of Figure 9. This constellation will hereafter be referred to as "constellation $2 "$ in impression II-W- 1 because it was formed about minutia 2 as a focal point. Constellations which do not include at least $W$ minutiae points are rejected. Current $1 \mathrm{y}, \mathrm{W}=4, \mathrm{~d}=20 \mathrm{~mm}$, and $\alpha=12^{\circ}$ 。

\subsection{Constellation Selector}

Since each minutia point takes its turn as a focal point trying to form a constellation, there will be some duplication of constellations. Accordingly, Flow Chart 2 details a procedure whereby any constellation that is equal to or included in another constellation is rejected. At the conclusion of the constellation generation and selection (Connector IV in Flow Chart 2), the data for impression II-W- 1 in Figure 7 yields the four constellations shown at the left of Figure 9. Figure 9 also shows the two constellations that are generated from the data in Figure 7 for impression II-W-2.

\section{$3.3^{\circ}$ Coordinate Transformer}

Each constellation next undergoes a coordinate transformation. The center of gravity of the constellation is determined by computing the average value of the $X$ and the average value of the $Y$ coordinates. The coordinates $X^{\prime}$ and $Y^{\prime}$ of each point relative to this center of gravity are then computed as detailed in Flow Chart 3. The new coordinates for constellation 2 consisting of points $2,4,5$, and 8 in impression II-W- 1 are shown in Figure 10. Figure 10 also gives values for $Z$ which is the direction of a minutia relative to the $X$ axis. $Z=1$ means that the minutia points upward and $\mathrm{Z}=0$ means that the minutia points downward. $\mathrm{Z}$ is readily determined from $\theta$ as shown in boxes 53 and 54 of Flow Chart 3. Figure 10 also gives the non-directed angle $\beta$ of each minutia. If $\theta<180$ then $\beta=\theta$. If $\theta \geq 180$ then $\beta=\theta-180$. 
In the final step of the transformation, the coordinate axes are rotated so that the angle between the $g$ axis and the initial $x$ axis is equal to the average value of the angle $\beta$. In effect the $y$ axis of the new coordinate system is aligned with the constellation. The coordinates of the minutiae in constellation 2 relative to this $x$ - $y$ coordinate system are shown in Figure 11.

\subsection{Descriptor Generator}

If the minutiae in constellation 2 are arranged in order according to the values of $\mathcal{X}$ and $\mathcal{Y}$ in Figure 11 , they can be exhibited on a grid as shown in Figure 12. The value of $\mathrm{Z}$ determines whether a minutia points up or down. The constellation is now in a measure-independent form。 By comparing Figure 12 with the same minutiae in Figure 4 it will be seen that the minutiae have retained their positions and up-or-down directions relative to each other but distances between points and variations in the angles between minutiae have become irrelevant.

The descriptor $\mathrm{d}_{4} \mathrm{u}_{4}-\mathrm{d}_{3} \mathrm{u}_{3}-\mathrm{d}_{2} \mathrm{u}_{2}-\mathrm{d}_{1} \mathrm{u}_{1}$ for constellation 2 is 10-01-12-03. This can be determined by inspecting Figure 12 as follows: $\mathrm{d}$ is the direction of the corresponding minutia and is equal to $\mathrm{Z}$ for this minutia. The value of u for each minutia is read from the scale along the $\mathrm{Y}$ axis. For example $\mathrm{d}=1$ for minutia point 4 because 4 point upward and $u=2$ as read from the $Y$ scale. The detailed procedure for this computation of descriptors is given in Flow Chart 4.

\subsection{Descriptor Compression}

It may be desirable to compress the information in a descriptor into a binary integer for the purpose of minimizing the amount of storage space that will be required in the file. One method for compressing a descriptor is illustrated in Figure 13. The right-most five bits contain the integer $\mathrm{N}$, where $\mathrm{N}$ is the number of minutiae in the constellation. The next $\mathrm{N}$ bits to the left give the values of $\mathrm{d}_{\mathrm{N}}, \mathrm{d}_{\mathrm{N}-\mathrm{I}},---, \mathrm{d}_{1}$. The rest of the bits to the left represent the integer $\mathrm{A}^{\mathrm{N}}$ whose derivation is described below.

Since the integers $u_{N}, u_{N-1},--, u_{1}$ are a string of permuted numbers, there are N! permutations of these numbers. Accordingly, each permutation can be identified with an integer $A$ between 0 and $N$ !-1 inclusive. For example, if $\mathrm{N}=4$, each string of $\mathrm{u}^{\prime} \mathrm{s}$ can be related to a value of $\mathrm{A}$ as follows: 


\begin{tabular}{|c|c|}
\hline $\mathrm{u}_{4} \mathrm{u}_{3} \mathrm{u}_{2} \mathrm{u}_{1}$ & A \\
\hline $\begin{array}{llll}0 & 1 & 2 & 3\end{array}$ & 0 \\
\hline $\begin{array}{llll}0 & 1 & 3 & 2\end{array}$ & 1 \\
\hline $\begin{array}{llll}0 & 2 & 1 & 3\end{array}$ & 2 \\
\hline-- & \\
\hline $\begin{array}{llll}3 & 2 & 0 & 1\end{array}$ & 22 \\
\hline $\begin{array}{llll}3 & 2 & 1 & 0\end{array}$ & 23 \\
\hline
\end{tabular}

Flow Chart 5 gives a detailed procedure for computing the value of $\mathrm{A}$ corresponding to any given string of u's. This procedure, from the art of orderly listing permutations, is based on the lexicographical method of D.H. Lehmer。3. The total number of bits in the compressed descriptor is a function of $\mathrm{N}$ and this information may be utilized in packing the descriptors into the file. In the design of an automated fingerprint system the time needed for computing the compression and expansion of a descriptor must be weighed against the amount of file space that will be saved.

The four descriptors for impression II-W- 1 and the two descriptors for impression II-W-2, shown in Figure 14, result from the data shown in Figure 7. The compressed forms of these descriptors are shown as octal integers for convenience. The impression identification name (Ident) II-W- 1 and its set of four descriptors are now written in the electronic file as shown in Figure 2. A similar procedure is carried out for impression II-W-2 and, of course, the descriptors for other fingerprint impressions may also be placed in the file. In a practical application of this system it would be undesirable to store the identifying name (Ident) in the file. Instead the filing computer might supply a number to the fingerprint reader which is a unique function of the location in the file where the fingerprint descriptor is stored. This number would be written on the fingerprint card and would become the serial number which determines where the fingerprint card is filed.

\section{Matching Fingerprint Descriptors}

The matcher shown at the right in Figure 2 is used for studying the effectiveness of the descriptor design. Descriptor sets for two different fingerprint impressions in the file, named IdentA and IdentB, are read from the file and compared. A score ST is printed by the computer indicating how well the descriptors match. The impressions being compared may be from the same or different fingers and, of course, the score ST should be high if the impressions are from the same finger and low if the impressions are from different fingers. Various parameters

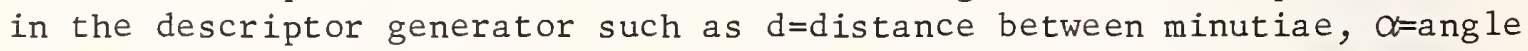
between minutiae directions, and $W=$ minimum number of minutiae required to form a constellation can be varied while the resulting score ST is observed. The next section describes one of several experimental methods for matching descriptors. 
An operator typing in two identifying impression names such as II-W-1 and II-W-2 wil1 cause the computer to retrieve the set of compressed descriptors corresponding to each of these impressions. Each compressed descriptor is then expanded into its original form by the inverse of the procedure illustrated in Figure 13. The permuted numbers are generated from the integer $\mathrm{A}$ by the procedure detailed in Flow Chart 6.

Assume now that the computer contains the two sets of descriptors shown in Figure 14. The computer will next proceed to compare each descriptor of impression II-W- 1 with each descriptor of impression II-W-2 and accumulate a score ST as it proceeds. The comparison of the descriptor for constellation 41 in impression II-W-1 with constellation 41 in impression II-W-2 will be used in explaining the procedure. The pictographs for these constellations are shown in Figure 15. The minutiae are compared from right-to-left. They are also compared from top-tobottom, and to facilitate the latter comparison, a second descriptor is computed for each constellation. If a pictograph in Figure 15 is rotated $90^{\circ}$ clockwise, the new descriptor $\mathrm{e}_{4} \mathrm{v}_{4} \mathrm{e}_{3} \mathrm{v}_{3} \mathrm{e}_{2} \mathrm{v}_{2} \mathrm{e}_{1} \mathrm{v}_{1}$ is derived in the same way that was described earlier in this paper in the section labeled Descriptor Generator. However, now each direction bit $e=1$ if the minutiae points to the right and $e=0$ if the minutia points to the left. The resulting descriptors are shown at the right of each pictograph in Figure 15 and the details of their computation are given in Boxes 6, 7, and 8 in Flow Chart 7 .

The minutiae in each pair of constellations such as those shown in Figure 15 are next compared three at-a-time working from right-to- left and also from top-to-bottom. The method for accomplishing this is illustrated by grouping the minutiae in $3 \times 3$ pictographs working from left-to-right. This is illustrated in Figure 16 for constellation 41 of impression II-W-1. The direction bits are converted to octal equivalents (reading backward) and the permutations are converted-to their orderedlist equivalents as described earlier in the section on Descriptor Compression. For convenience in hand calculation, the following conversion table can be used.

$\begin{array}{cc}\text { Permutation } & \text { a } \\ 210 & 0 \\ 120 & 1 \\ 201 & 2 \\ 021 & 3 \\ 102 & 4 \\ 012 & 5\end{array}$


The details for computing the horizontal triads $a_{N-2} b_{N-2}-a_{1} b_{1}$ from from the rotated descriptor $e_{N} v_{N}--e_{1} v_{1}$ are given in Boxes $9-23$ in Flow Chart 7. The results for the illustrative example are given in Figure 17.

\subsection{Triad Matching}

For each pair of constellations being matched, each ab triad in the first constellation is compared with each ab triad in the second constellation. When two of these triads are found to be equal, a score $S$ is set equal to 1 and the next successive triads from the constellations are compared. If these are found to be equal the score is increased by 1. This procedure is repeated until either string of triads is exhausted. The score $S$ resulting from this run of matches is compared with the score resulting from any other run of matches that may occur for the same pair of ab strings. The largest of these scores is designated S1. Matching the two ab strings in Figure 17 results in only one run and the final score is $\mathrm{S} l=3$. The details for this computation are given in Flow Chart 8.

The two fg strings from the same pair of constellations are next matched as described above. The score for the example in Figure 17 is $\mathrm{S} 2=2$. The total score for the constellation match is SS=S1+S2, and $\mathrm{SS}=5$ in the example. Any score SS that is equal to or greater than a threshold score SL is retained and all others are rejected. In a practical application of this identification system the parameter SL might be set low when searching for latent fingerprints and be set higher when searching for regular fingerprints.

The total score ST resulting from matching two impressions is equal to the sum of all SS scores resulting from matching the various pairs of constellations from the two impressions. The scores resulting from matching the two impression fragments whose minutiae data is given in Figure 7 are shown in Figure 18. The total score, ST=8, includes two legitimate constellation matches (41-41 and 40-41) producing a total score of 6 and a false match (40-2) producing a score of 2. False matches produce a certain amount of "noise" in the score and it may be desirable to reduce this noise by filtering. 


\section{Conclusions}

Complete sets of descriptors have been computed for a few fingerprint impressions from the same and different fingers. The parameters used were $d=20 \mathrm{~mm}, \alpha=12^{\circ}$, and $W=4$. When the descriptors for two impressions from different fingers were compared, the score ss resulting from comparing pairs of constellations was found to occasionally have values of 1,2 , or 3 but seldom more than 3. Most of these scores, indicating false matches or noise, were therefore eliminated from the accumulated score ST by setting the parameter SL=4 in the matcher program. Then a further improvement in scoring was found by defining a new score sK equal to the score ST with SL=4 divided by the score ST with SL=1. The SK scores resulting from comparing various pairs of impressions from the same finger were found to be generally higher than SK scores resulting from comparing the impressions from different fingers.

Based on the limited amount of fingerprint data processed to date, the procedure described in this paper offers promise as a basis for a single-fingerprint classification system. Many more fingerprint impressions must be processed, and optimum values must be found for the various parameters corresponding to the characteristics of the minutia reader used. Also, a method of ordering the descriptor sets is needed so that fingerprints can be classified and filed in a manner that will minimize search time. It may be possible to further reduce the amount of information filed in the descriptors and further improvement may be possible in the matcher. For example, matching quads instead of triads may offer some advantage. Finally, the computer time required for matching must be reduced to the lowest possible value.

\section{References}

1. The Science of Fingerprints, U.S. Government Printing Office, 1963

2. Cummins, H. and Midlo, C., Finger Prints, Palms and Soles, Dover Publications, Inc., New York, 1961 , p。 155

3. Beckenbach, E.F. (ed), Applied Combinatorial Mathematics, John Wiley and Sons, New York, 1964 , p. 20

The author is indebted to the Identification Division of the Federal Bureau of Investigation for its assistance in the preparation of this paper. The author is particularly indebted to Mr. J.F. Rafferty of the National Bureau of Standards who wrote the computer programs specified by the Flow Charts in this paper and who computed the results given here using the NBS Research Computer Facility. 


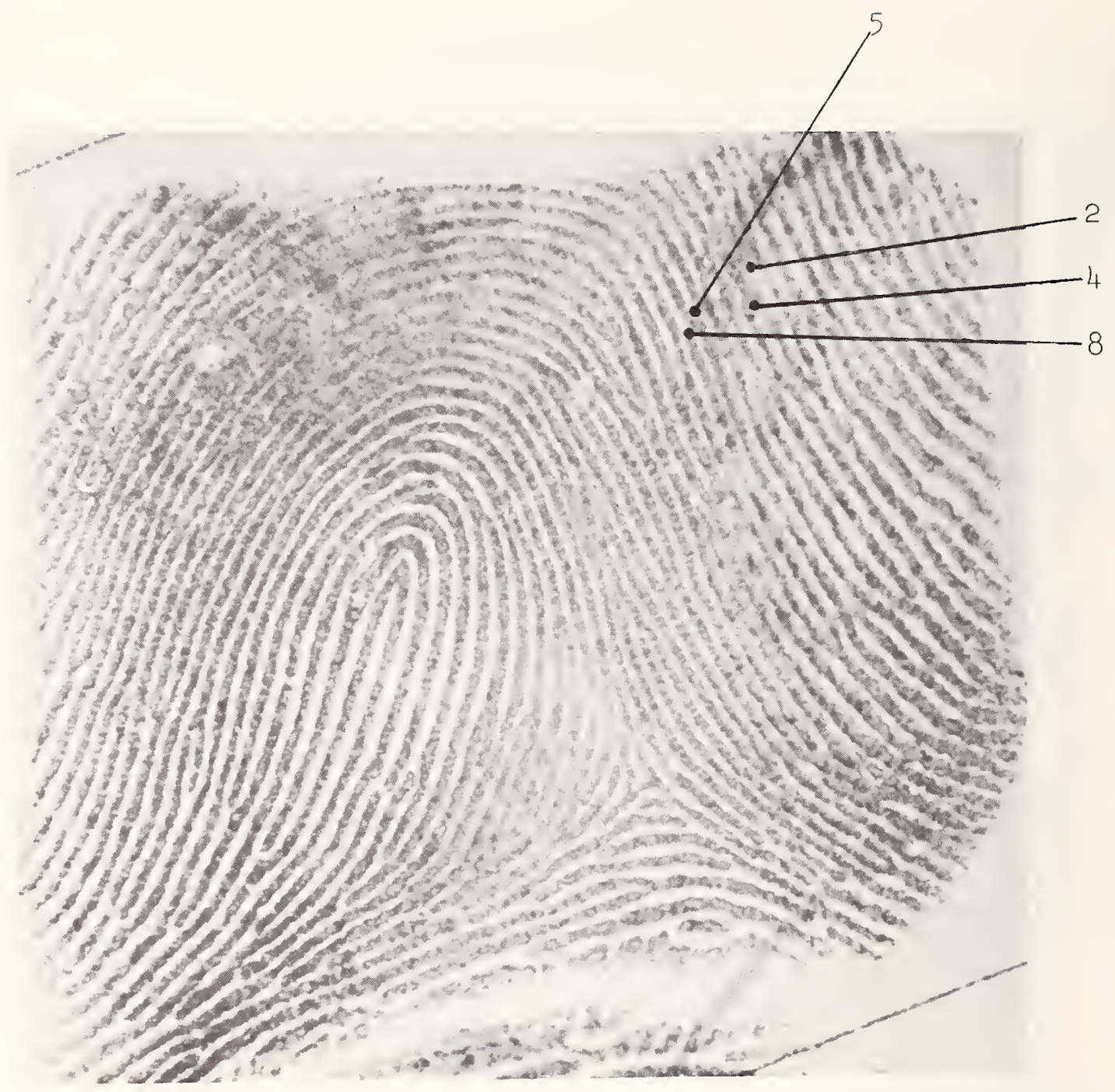

Figure 1 -- Fingerprint Impression II-W-2 


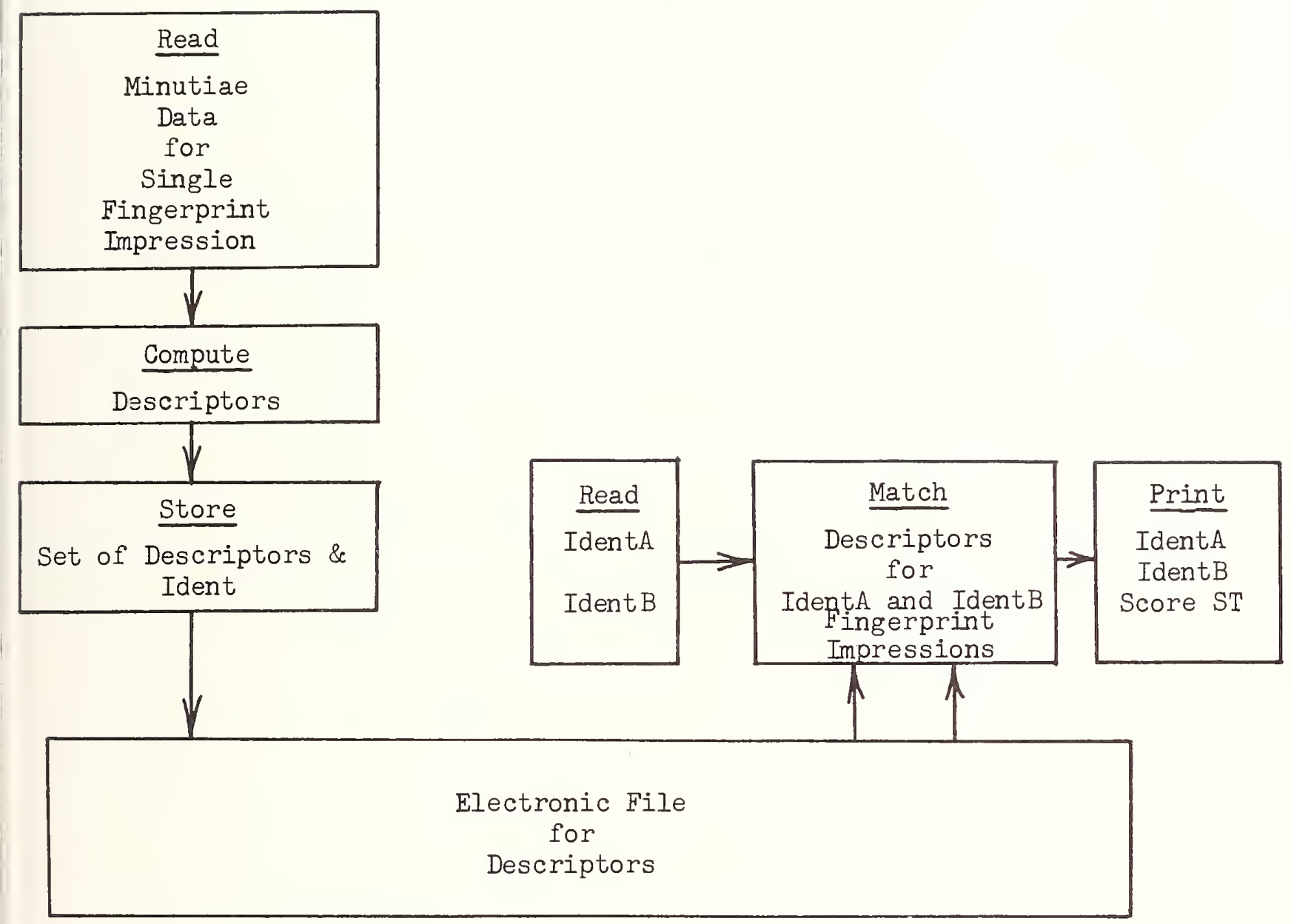

Figure 2 - Computerized system for experimentally identifying fingerprints 


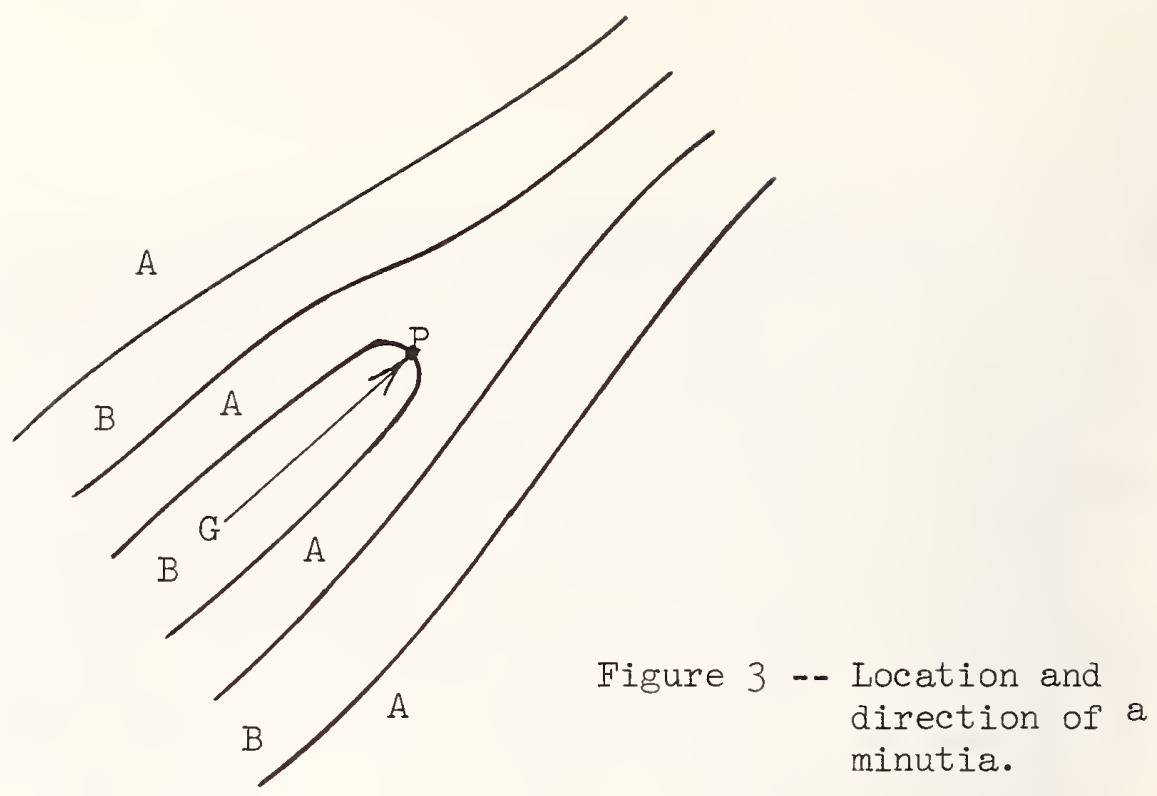



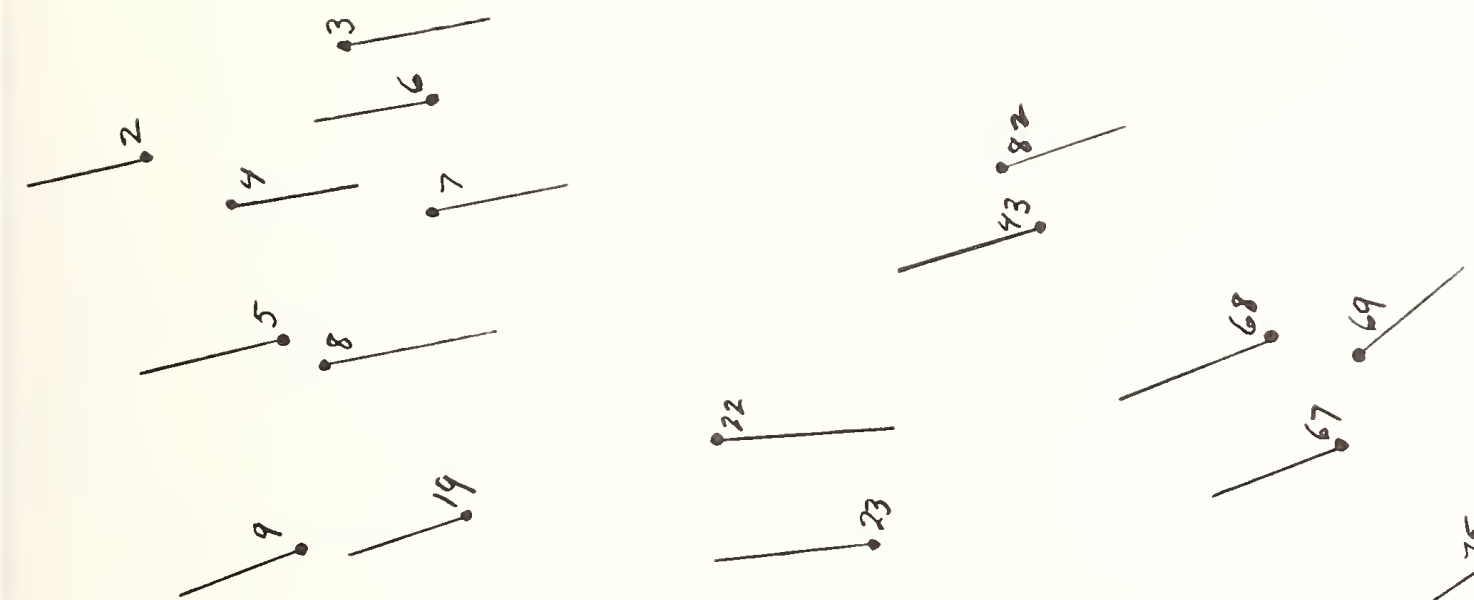

?
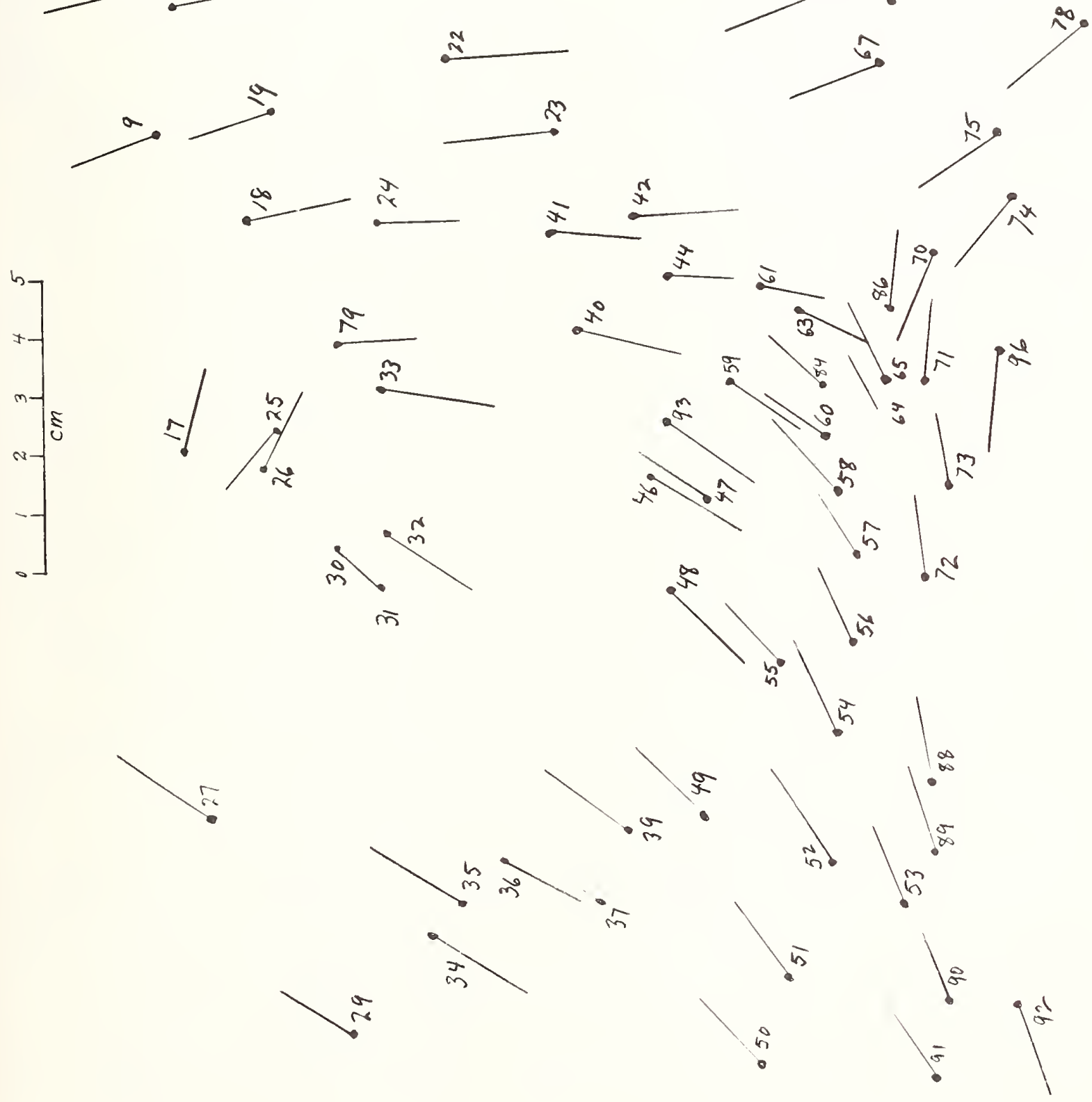

Figure 4 -- Minutiae from impression II-W-I 

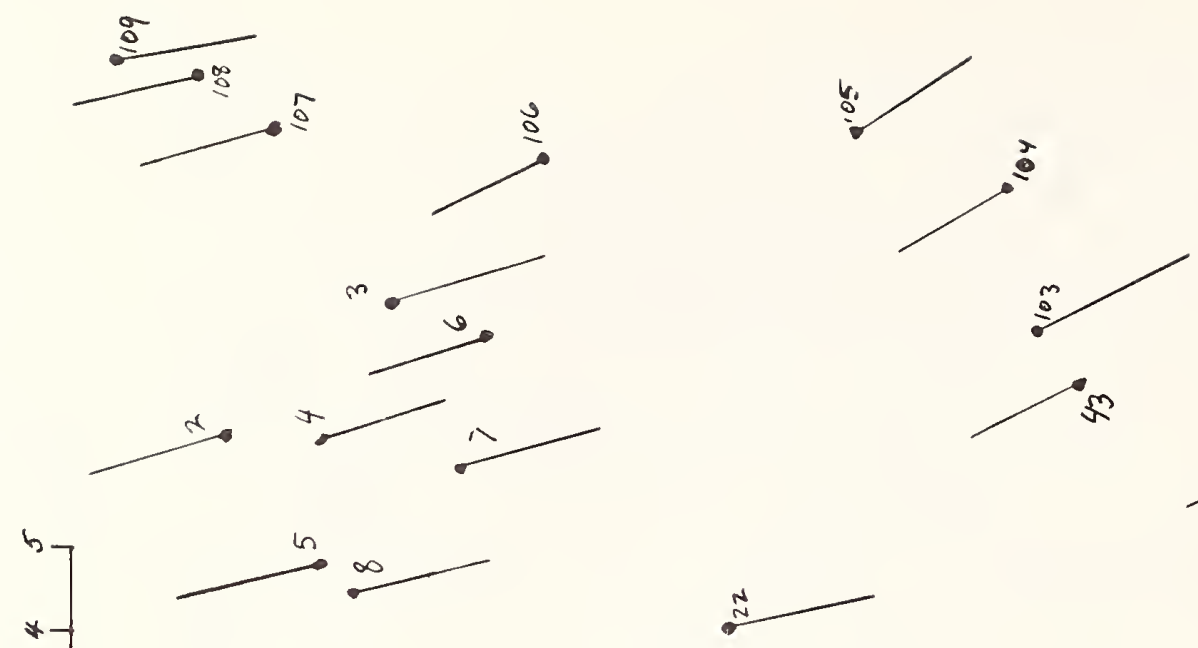

$\stackrel{n}{=}$
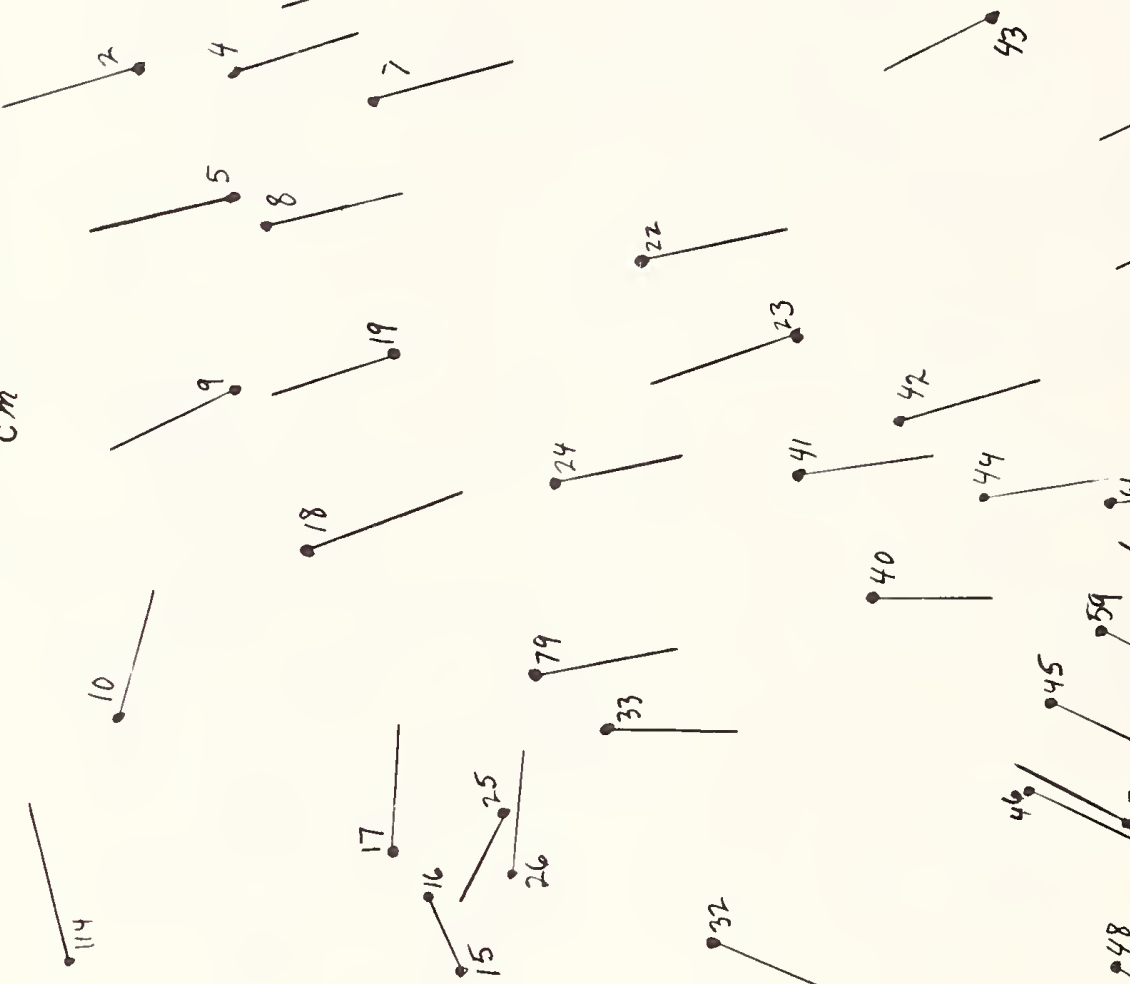

$\underset{0}{0}$
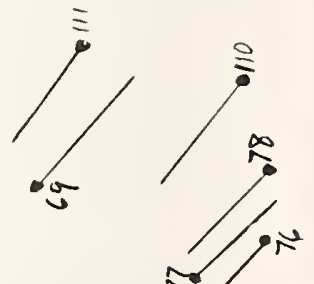

$-1$

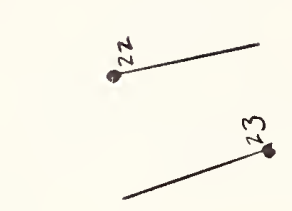

5
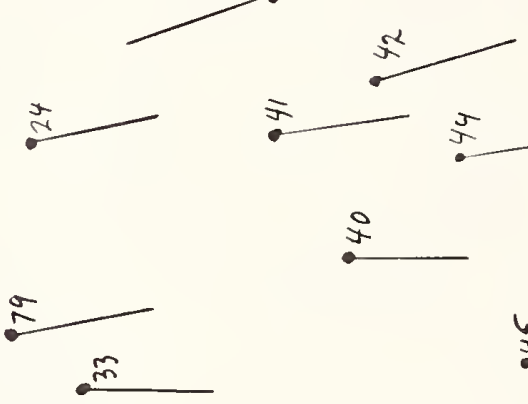

군

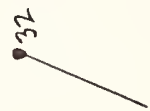

5
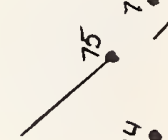

,
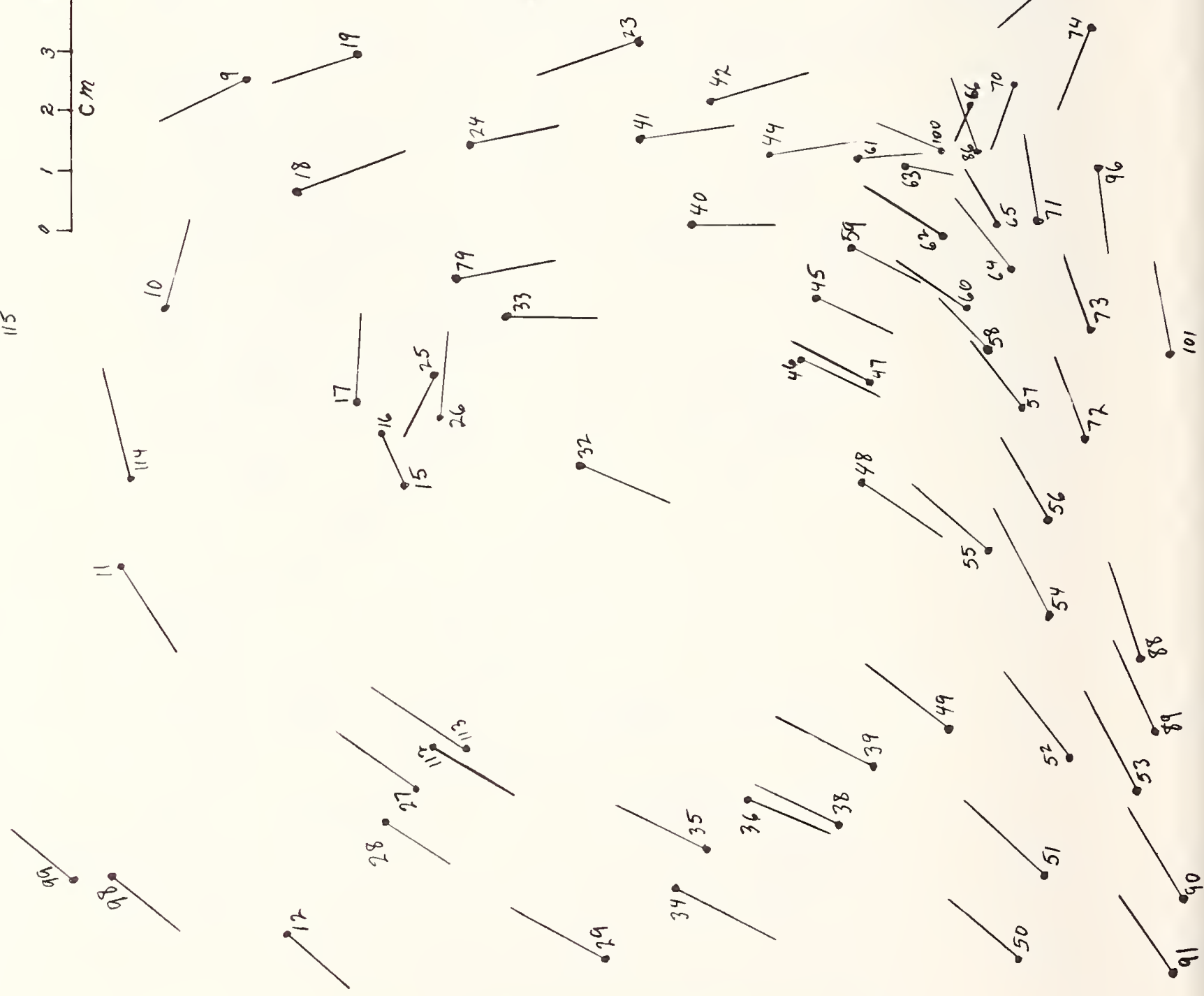


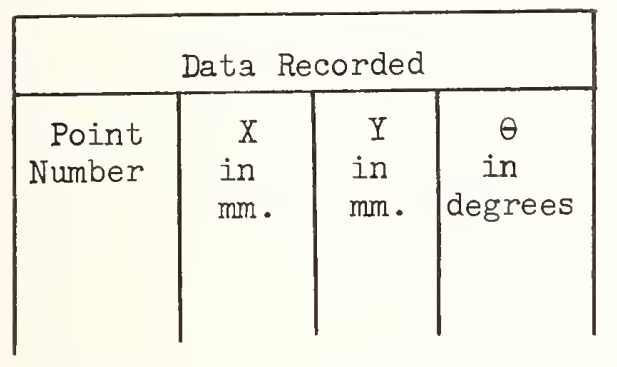

Figure 6 - Method ased for recording minutiae data

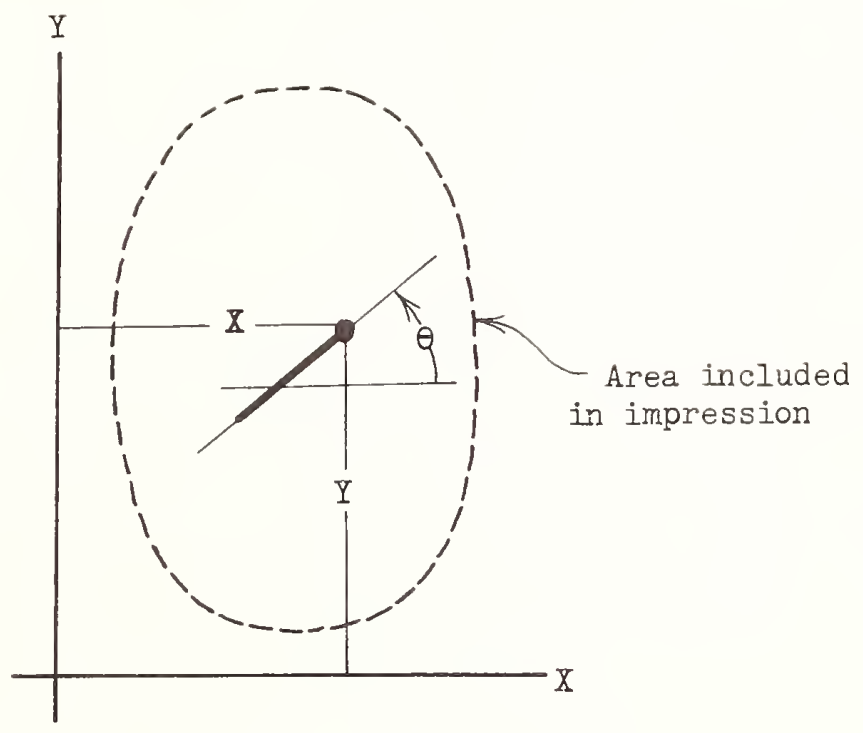

Fingerprint Impression II-W-2 \begin{tabular}{cccc}
$p$ & $X$ & $Y$ & $\theta$ \\
\hline 2 & 203 & 221 & 293
\end{tabular}

3221200101

4200210110

$5 \quad 185201294$

$\begin{array}{llll}6 & 216 & 188 & 290\end{array}$

$\begin{array}{llll}7 & 203 & 186 & 111\end{array}$

$8 \quad 183 \quad 195 \quad 112$

$9 \quad 161194301$

$\begin{array}{lllll}22 & 183 & 148 & 104\end{array}$

$\begin{array}{lllll}23 & 174 & 127 & 287\end{array}$

$\begin{array}{llll}40 & 142 & 117 & 87\end{array}$

$41 \quad 157 \quad 125 \quad 95$

42163111104

$\begin{array}{llll}43 & 215 & 115 & 298\end{array}$

$\begin{array}{llll}44 & 154 & 103 & 97\end{array}$

$\begin{array}{llll}61 & 155 & 088 & 89\end{array}$

$\begin{array}{llll}63 & 152080 \quad 75\end{array}$

$\begin{array}{llll}53 & 051 & 044 & 213\end{array}$

$\begin{array}{llll}88 & 078 & 043 & 202\end{array}$

$\begin{array}{lllll}89 & 066 & 041 & 209\end{array}$

$\begin{array}{llll}90 & 042 & 033 & 214\end{array}$

$92043022 \quad 30$ \begin{tabular}{cccc}
$\mathrm{p}$ & $\mathrm{X}$ & $\mathrm{Y}$ & $\theta$ \\
\hline 2 & 199 & 208 & 290
\end{tabular}

3216190110

$4 \quad 200197111$

$5 \quad 185196287$

$\begin{array}{llll}6 & 213 & 179 & 291\end{array}$

$\begin{array}{llll}7 & 197 & 181 & 109\end{array}$

$\begin{array}{llll}8 & 182 & 192 & 107\end{array}$

23173129293

$\begin{array}{lllll}40 & 143 & 118 & 94\end{array}$

$41 \quad 156 \quad 128 \quad 102$

$42164116 \quad 110$

44156106102

6115609198

Figure 7 - A portion of minutiae data used for demonstrating descriptor generation and matching 


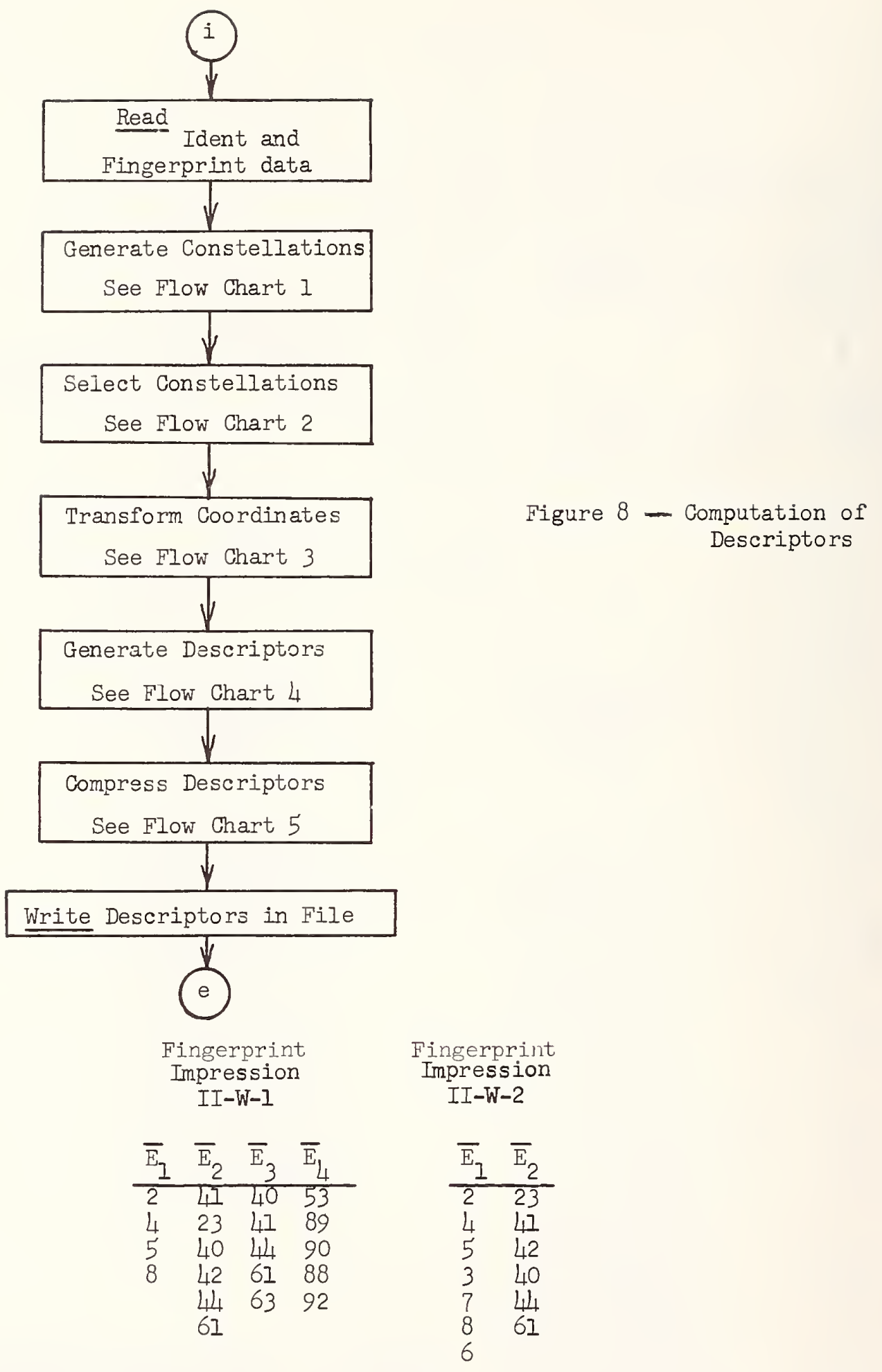

Figure 9 - Constellations Selected 


$$
\begin{gathered}
\text { Impression II-W-I } \\
\text { Constellation } 2
\end{gathered}
$$

\begin{tabular}{rrrrr}
$\mathrm{p}$ & \multicolumn{1}{c}{$\mathrm{X}^{\prime}$} & \multicolumn{1}{c}{$\mathrm{Y}^{\prime}$} & $\mathrm{Z}$ & $\beta$ \\
\hline 2 & 10.25 & 14.25 & 0 & 113 \\
4 & 7.25 & 3.25 & 1 & 110 \\
5 & -7.75 & -5.75 & 0 & 114 \\
8 & -9.75 & -11.75 & 1 & 112
\end{tabular}

\footnotetext{
Figure 10 - Minutiae, coordinates, and directions relative to coordinate axes at constellation's center of gravity
}

Impression II-W-I

Constellation 2

\begin{tabular}{rrrr}
$\mathrm{p}$ & \multicolumn{1}{c}{$y$} & $y$ & $\mathrm{z}$ \\
\hline 2 & 14.88 & 9.30 & 0 \\
4 & 7.94 & .26 & 1 \\
5 & -9.35 & -2.38 & 0 \\
8 & -13.47 & -7.17 & 1
\end{tabular}

Figure 11 - Minutiae coordinates relative to rotated axes. 
Impression II-W-I

Constellation 2

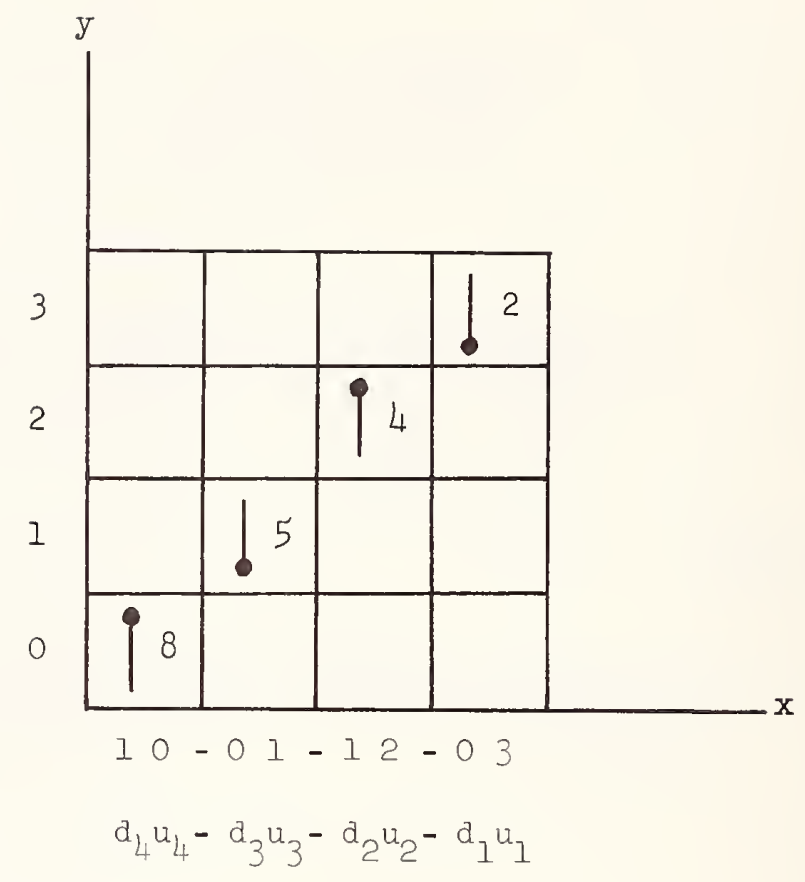

Figure 12 - Measure-independent constellation and resultant descriptor

Impression II-W-I

Constellation 2

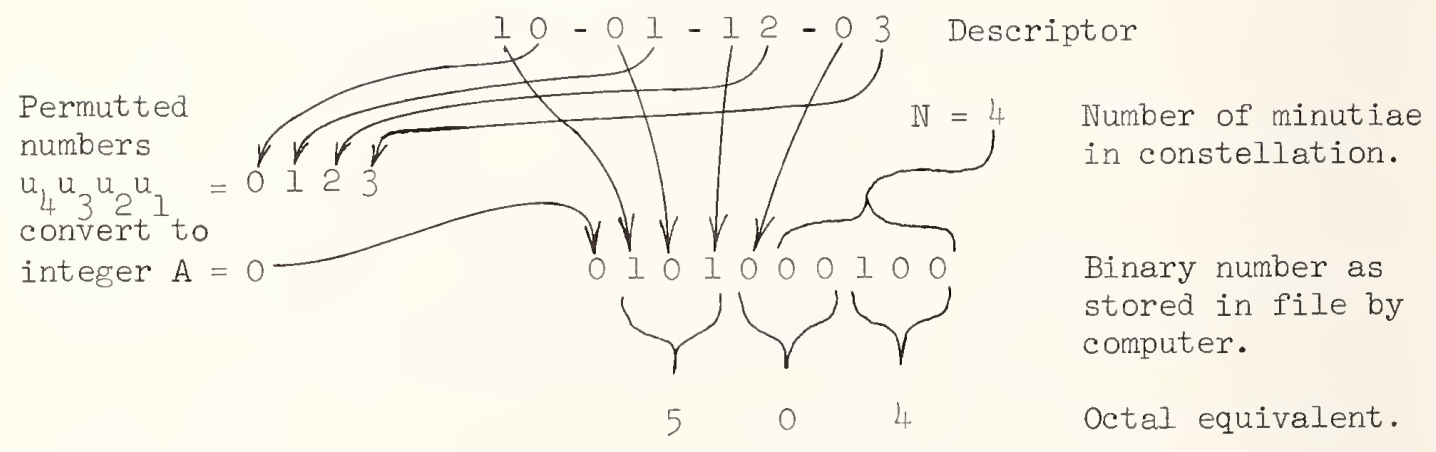

Figure 13 -- Compression of descriptor for storage in electronic file 
Impression II-W-I

Constellation

2

41

40

53

\begin{tabular}{llc}
2 & \multicolumn{2}{c}{ Impression II-W-2 } \\
41 & $8,5,7,4,2,6,3$ & $14-05-11-13-06-00-12$ \\
& $40,61,44,41,42,23$ & $13-10-11-15-12-04$
\end{tabular}

Figure 14 - Descriptors corresponding to fingerprint shown in Figure 7
Minutiae in

Constellation

$8,5,4,2$

$40,61,44,41,42,23$

$40,63,44,61,41$

$13-10-12-11-14$

$02-01-03-04-10$

Descriptor

10-01-12-03

$13-10-11-14-12-05$

$53,88,89,90,92$

$13-10-11-15-12-04$
Octal Form of Compressed Descriptor

504

2653705

225745

162045

65105447

266370.5
Impression II-W-I

Constellation 41

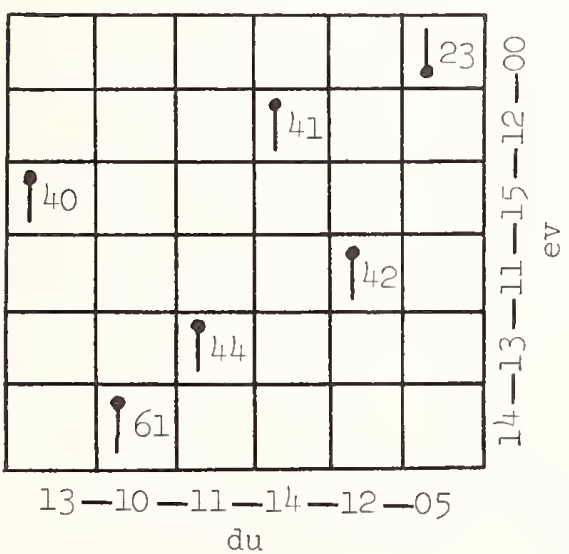

Impression II-W-?

Constellation 41

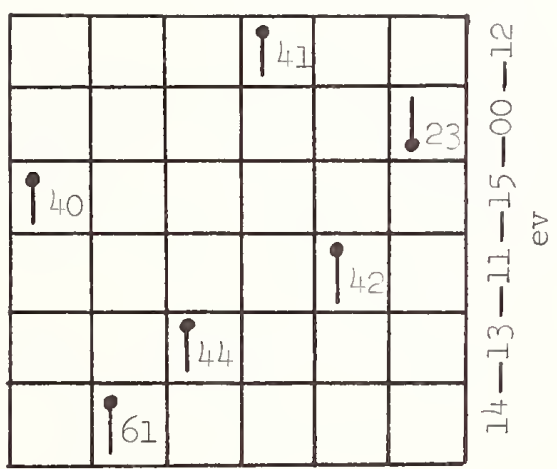

$13-10-11-15-12-04$

Figure 15 - Pictographs of the same constellation from two different fingerprint impressions 


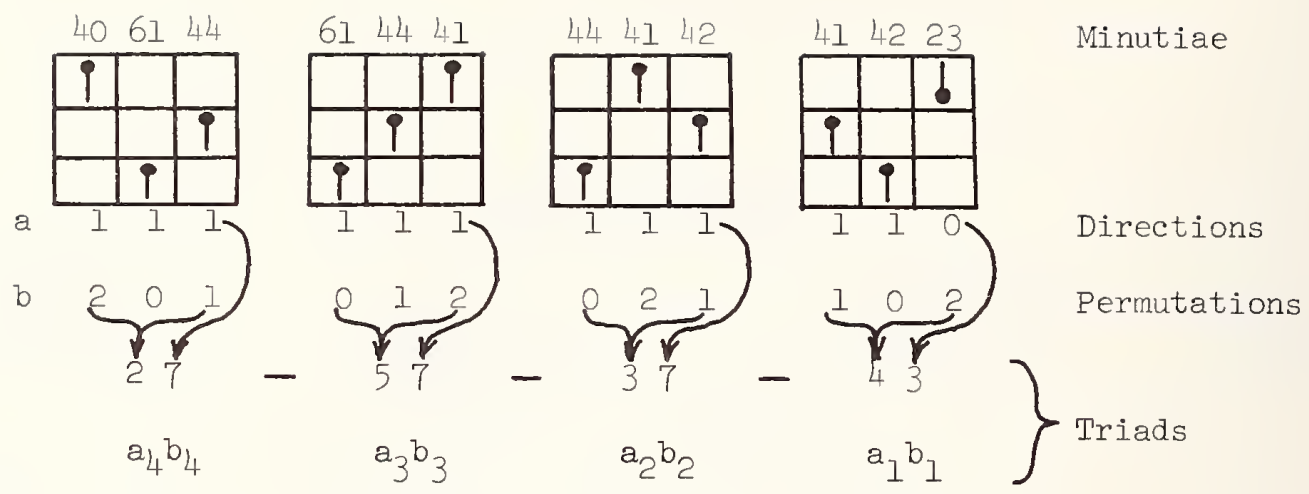

Figure 16 - Derivation of horizontal triads for constellation 41 in fingerprint impression II-W-I

\begin{tabular}{|c|c|c|c|c|}
\hline & \multicolumn{2}{|c|}{$\begin{array}{l}\text { Impression II-W-I } \\
\text { Constellation } 4 I\end{array}$} & \multicolumn{2}{|c|}{$\begin{array}{l}\text { Impression II-W-2 } \\
\text { Constellation } 4 I\end{array}$} \\
\hline & Horizontal & Vertical & Horizontal & Vertical \\
\hline Descriptors & $\frac{d u}{13-10-11-14-12-05}$ & $\begin{array}{c}\mathrm{ev} \\
14-13-11-15-12-00\end{array}$ & $\frac{\mathrm{du}}{13-10-11-15-12-04}$ & $\begin{array}{c}\mathrm{ev} \\
14-13-11-15-00-12\end{array}$ \\
\hline Triads & $\begin{array}{c}a b \\
27-57-37-43\end{array}$ & $\begin{array}{c}f g \\
07-47-37-03\end{array}$ & $\begin{array}{c}a b \\
27-57-37-23\end{array}$ & $\begin{array}{c}f g \\
07-47-13-25\end{array}$ \\
\hline
\end{tabular}

Figure 17 - Descriptor and triad data for illustrative example

Impression II-W-I

Constellation

41

40

40
Impression II-W-2

Constellation

41

2

41
Score for Constellations

SI S2 SS

325

0 22

1001

Total Score

$$
\mathrm{ST}=8
$$




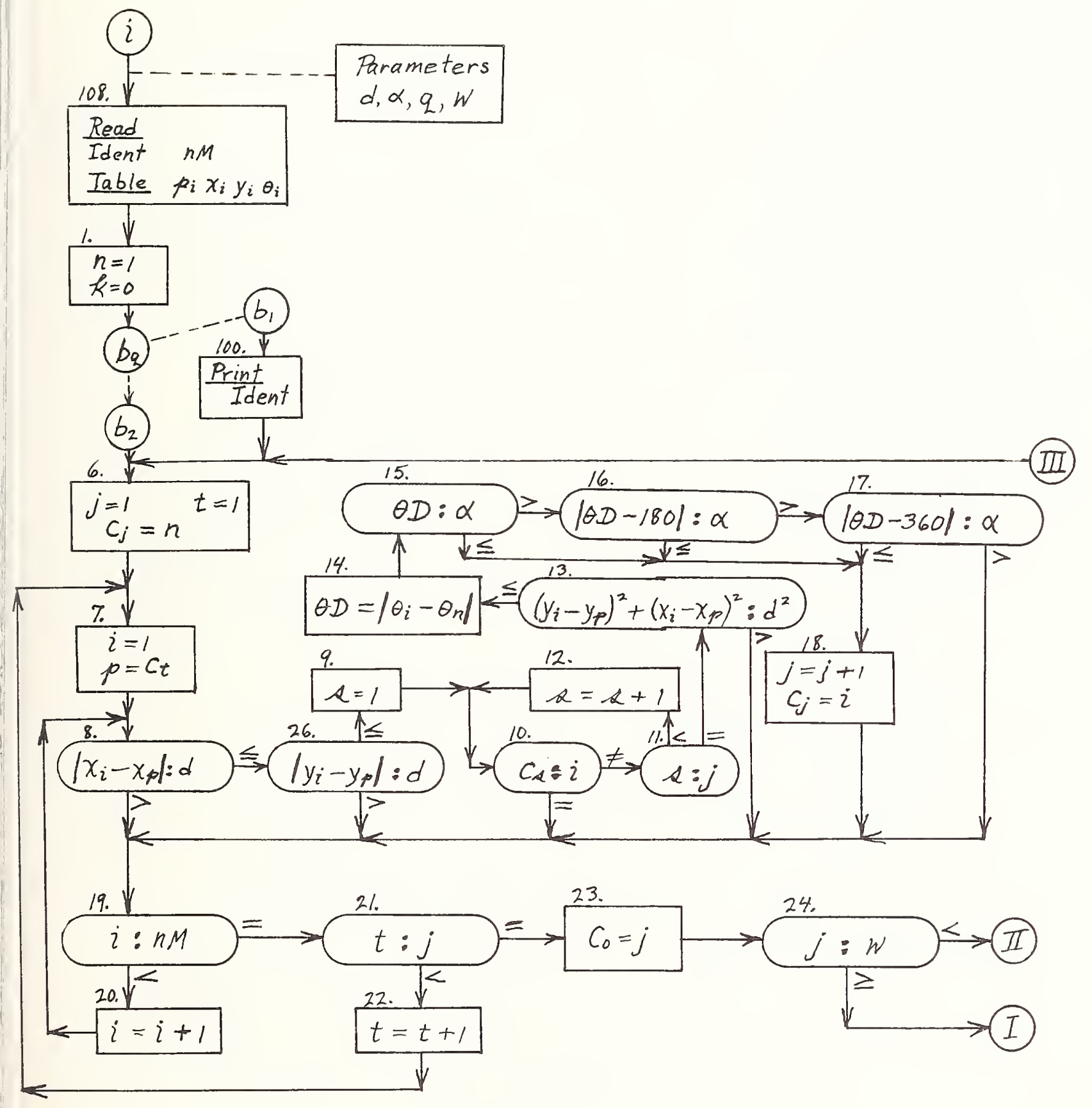

Flow Chart I. Constellation Generator 


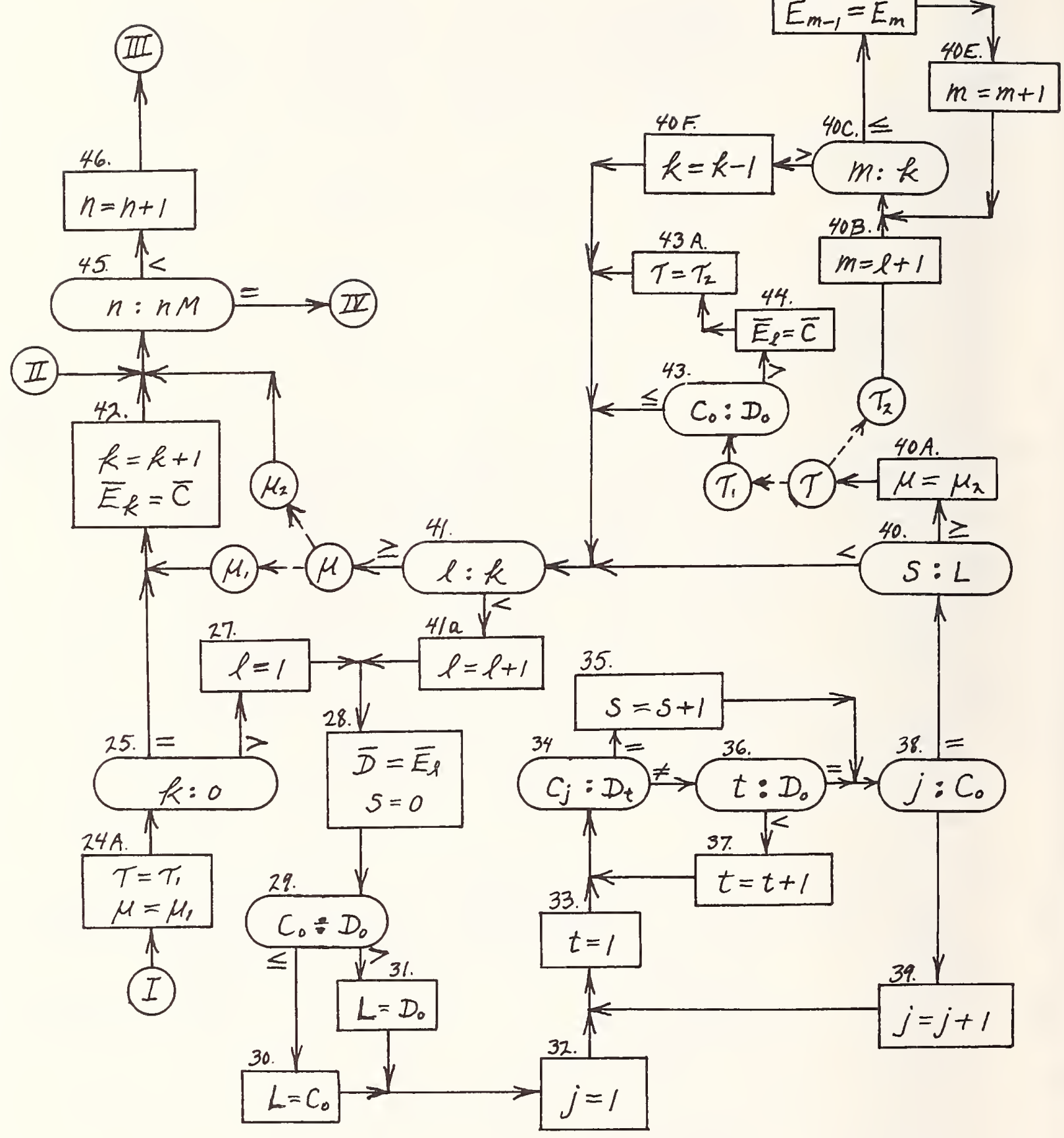

Flow Chart 2. Constellation Selector 


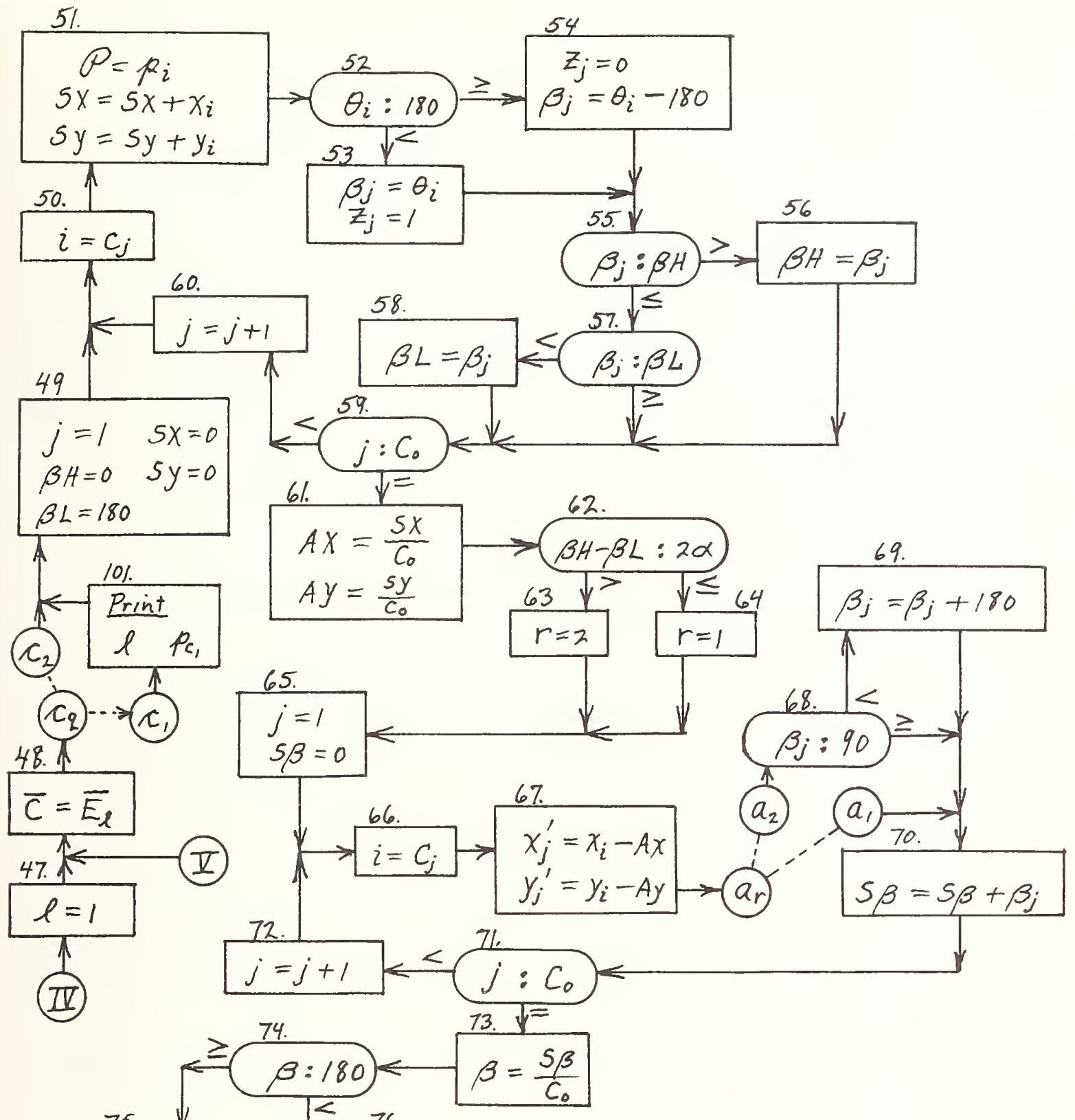

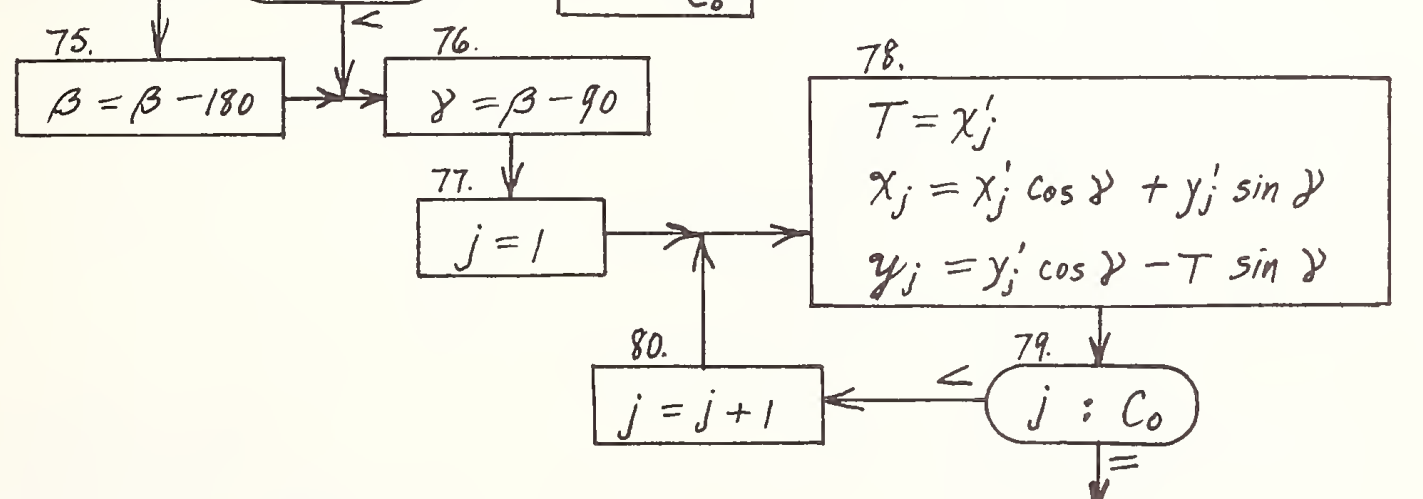

Flow Chart 3. Coordinate Trans former 


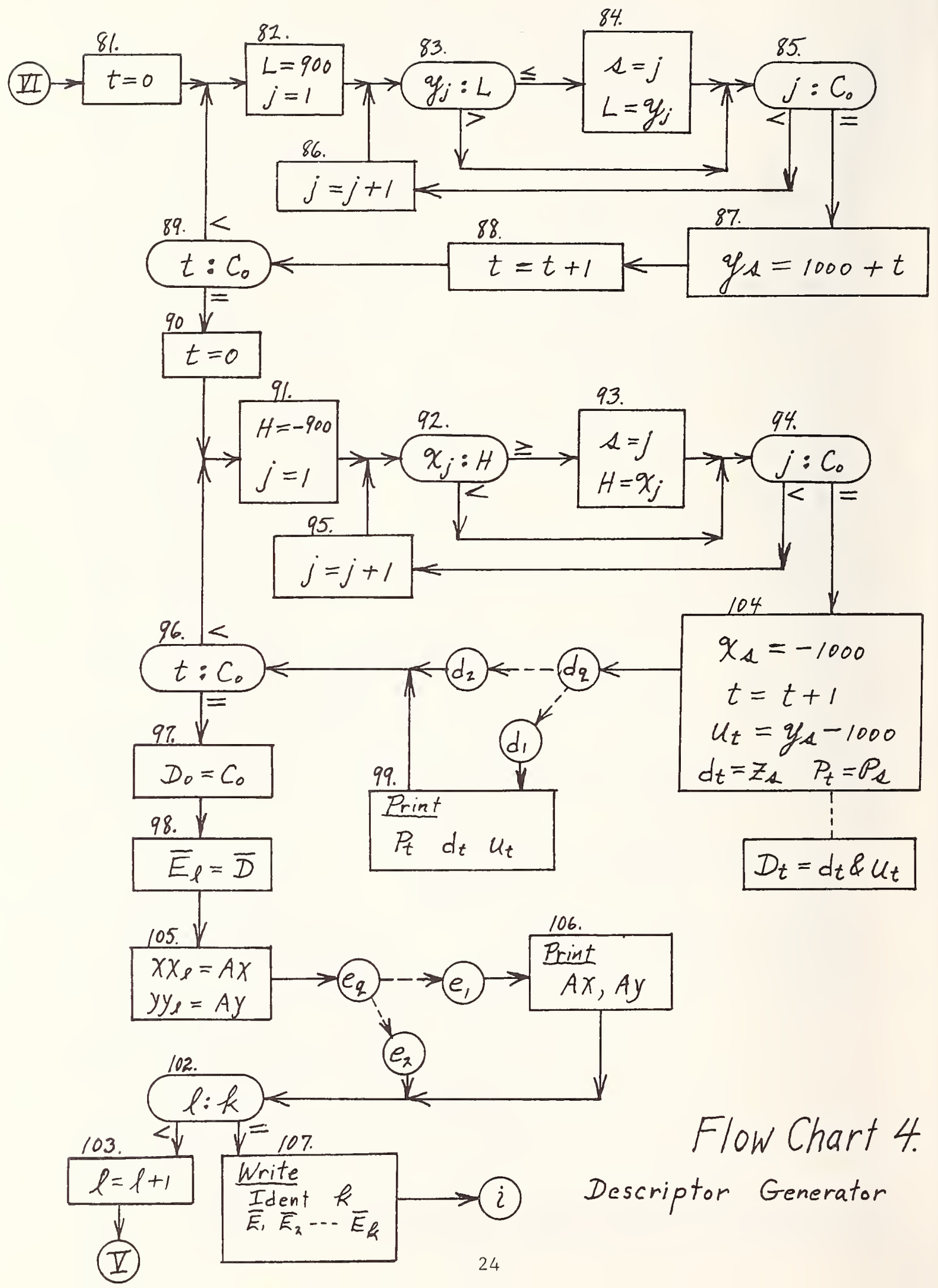



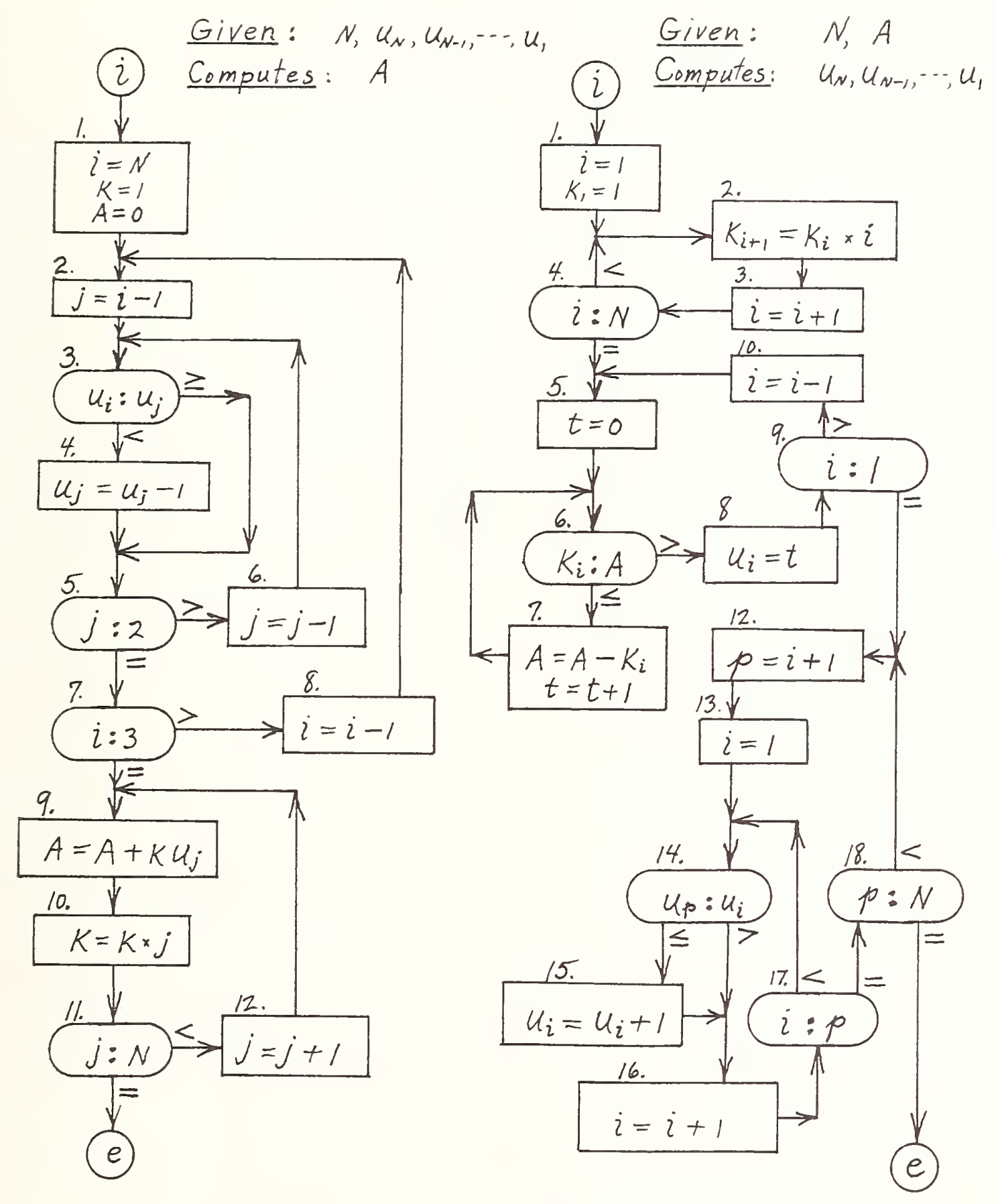

Flow Chart 5.

Flow Chart 6. 


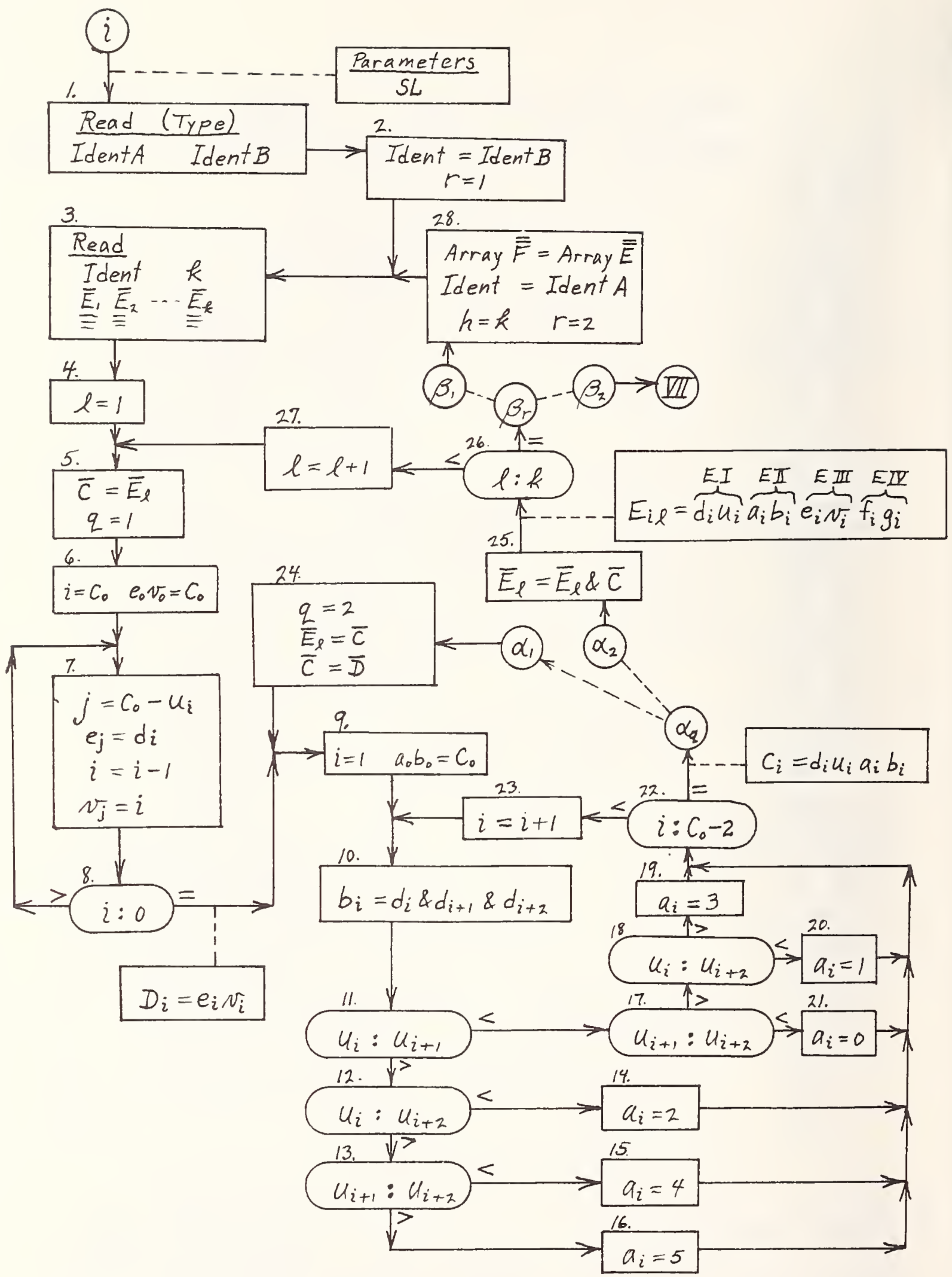

Flow Chart 7. Triad Generator 


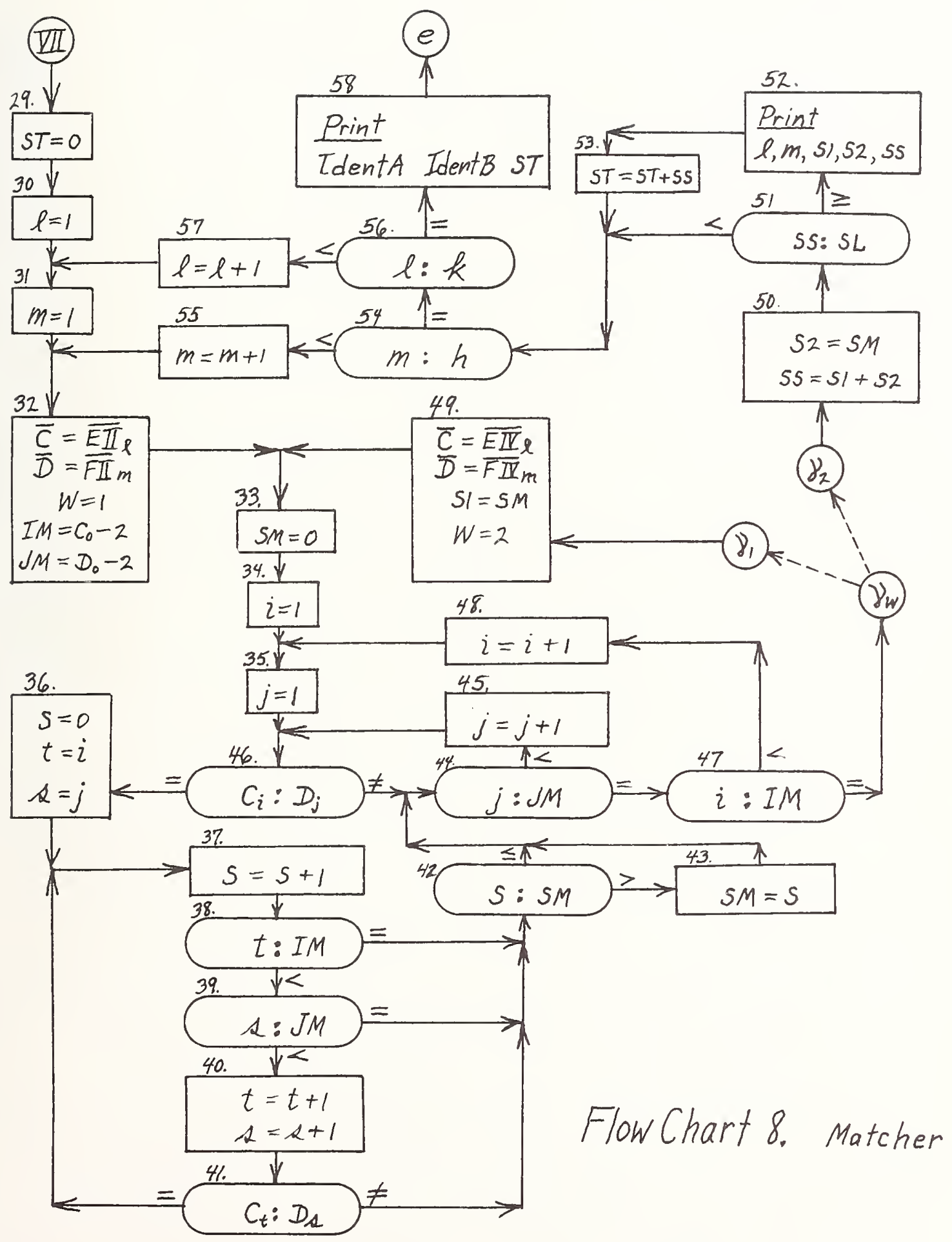





\section{PERIODICALS}

JOURNAL OF RESEARCH reports National Bureau of Standards research and development in physics, mathematics, chemistry, and engineering. Comprehensive scientific papers give complete details of the work, including laboratory data, experimental procedures, and theoretical and mathematical analyses. Illustrated with photographs, drawings, and charts.

Published in three sections, available separately:

\section{- Physics and Chemistry}

Papers of interest primarily to scientists working in these fields. This section covers a broad range of physical and chemical research, with major emphasis on standards of physical measurement, fundamental constants, and properties of matter. Issued six times a year. Annual subscription: Domestic, $\$ 5.00$; foreign, $\$ 6.00^{*}$.

\section{Mathematical Sciences}

Studies and compilations designed mainly for the mathematician and theoretical physicist. Topics in mathematical statistics, theory of experiment design, numerical analysis, theoretical physics and chemistry, logical design and programming of computers and computer systems. Short numerical tables. Issued quarterly. Annual subscription: Domestic, $\$ 2.25$; foreign, $\$ 2.75 *$.

\section{Engineering and Instrumentation}

Reporting results of interest chiefly to the engineer and the applied scientist. This section includes many of the new developments in instrumentation resulting from the Bureau's work in physical measurement, data processing, and development of test methods. It will also cover some of the work in acoustics, applied mechanics, building research, and cryogenic engineering. Issued quarterly. Annual subscription: Domestic, $\$ 2.75$; foreign, $\$ 3.50^{*}$.

\section{TECHNICAL NEWS BULLETIN}

The best single source of information concerning the Bureau's research, developmental, cooperative and publication activities, this monthly publication is designed for the industry-oriented individual whose daily work involves intimate contact with science and technology-for engineers, chemists, physicists, research managers, product-development managers, and company executives. Annual subscription: Domestic, $\$ 1.50$; foreign, $\$ 2.25^{*}$.

"Difference in price is due to extra cost of foreign mailing.
NONPERIODICALS

Applied Mathematics Series. tables, manuals, and studies.

Mathematical

Building Science Series. Research results, test methods, and performance criteria of building materials, components, systems, and structures.

Handbooks. Recommended codes of engineering and industrial practice (including safety codes) developed in cooperation with interested industries, professional organizations, and regulatory bodies.

Special Publications. Proceedings of NBS conferences, bibliographies, annual reports, wall charts, pamphlets, etc.

Monographs. Major contributions to the technical literature on various subjects related to the Bureau's scientific and technical activities.

National Standard Reference Data Series. NSRDS provides quantitative data on the physical and chemical properties of materials, compiled from the world's literature and critically evaluated.

Product Standards. Provide requirements for sizes, types, quality and methods for testing various industrial products. These standards are developed cooperatively with interested Government and industry groups and provide the basis for common understanding of product characteristics for both buyers and sellers. Their use is voluntary.

Technical Notes. This series consists of communications and reports (covering both other agency and NBS-sponsored work) of limited or transitory interest.

\section{CLEARINGHOUSE}

The Clearinghouse for Federal Scientific and Technical Information, operated by NBS, supplies unclassified information related to Governmentgenerated science and technology in defense, space, atomic energy, and other national programs. For further information on Clearinghouse services, write:

Clearinghouse

U.S. Department of Commerce Springfield, Virginia 22151

Order NBS publications from: Superintendent of Documents Government Printing Office Washington, D.C. 20402 
U.S. DEPARTMENT OF COMMERCE

WASHINGTON, D.C. 20230

OFFICIAL BUSINESS 